\title{
Prostate Apoptosis Response-4 Is Expressed in Normal Cholangiocytes, Is Down-Regulated in Human Cholangiocarcinoma, and Promotes Apoptosis of Neoplastic Cholangiocytes When Induced Pharmacologically
}

Antonio Franchitto, ${ }^{*}$ Alessia Torrice, ${ }^{\dagger}$ Rossella Semeraro, ${ }^{\dagger}$ Cristina Napoli, ${ }^{\dagger}$ Gennaro Nuzzo, ${ }^{\ddagger}$ Felice Giuliante, ${ }^{\ddagger}$ Gianfranco Alpini, ${ }^{\S}$ Guido Carpino, ${ }^{\pi}$ Pasquale Bartolomeo Berloco," Luciano Izzo, ** Antonio Bolognese, ${ }^{* *}$ Paolo Onori, ${ }^{\dagger \dagger}$ Anastasia Renzi, ${ }^{*}$ Alfredo Cantafora, ${ }^{\dagger}$ Eugenio Gaudio, ${ }^{*}$ and Domenico Alvaro ${ }^{\dagger}$

From the Department of Human Anatomy, University of Rome "Sapienza," Rome, Italy; the Division of Gastroenterology, the Department of Clinical Medicine, University of Rome,

"Sapienza," Rome, Italy, Polo Pontino; the Department of Surgery, ${ }^{\ddagger}$ Hepatobiliary Unit, Catholic University of the Sacred Heart School of Medicine, Rome, Italy; the Division Research, ${ }^{5}$ Central Texas Veterans Health Care System, Scott \& White and Texas AGM University Health Science Center College of Medicine, Temple, Texas; the Department of Health Science, "University of Rome "Foro Italico," Rome, Italy; "Paride Stefanini" the Department of General Surgery, and Organ Transplantation," University of Rome, "Sapienza," Rome, Italy; the Department of Surgery "P. Valdoni,"** "Sapienza" University of Rome; and the

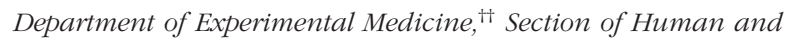
Clinical Anatomy, State University of L'Aquila, Italy

Prostate apoptosis response-4 (Par-4) is a tumor suppressor protein that sensitizes cells to apoptosis; therefore, Par-4 modulation has therapeutic potential. No data currently exist on Par-4 expression in cholangiocarcinoma (CCA). We evaluated the expression of Par- 4 in normal and neoplastic cholangiocytes and the effects of its pharmacological or genetic modulation. The study was performed in human and rat liver, CCA patient biopsies, and two CCA cell lines. PAR-4 was expressed in normal rat and human cholangiocytes, but its expression levels decreased in both human CCA and CCA cell lines. In both intrahe- patic and extrahepatic CCA, Par-4 expression (as shown by immunohistochemistry) was inversely correlated with markers of proliferation (eg, proliferating cellular nuclear antigen) and directly correlated with apoptotic markers (eg, Bax and Bax/BCL2 ratio). Par-4 expression was decreased during CCA cell proliferation but was enhanced after apoptosis induction. Pharmacological induction of Par- 4 expression in CCA cell lines by diindolymethane or withaferin A promoted activation of apoptosis and inhibition of proliferation. In contrast, specific Par- 4 silencing by small-interfering RNA determined activation of CCA cell line proliferation. Par- 4 is expressed in rat and human cholangiocytes and is down-regulated in both human CCA and CCA cell lines. Par- 4 protein levels decrease during cell proliferation but increase during apoptosis. Pharmacological or genetic induction of Par- 4 determines apoptosis of CCA cells, suggesting Par- 4 targeting as a CCA treatment strategy. (Am J Pathol 2010, 177:1779-1790; DOI: 10.2353/ajpath.2010.091171)

Cholangiocarcinoma (CCA) is a devastating cancer with a bad prognosis and scarce response to chemother-

Supported by the Dr. Nicholas C. Hightower Centennial Chair of Gastroenterology from Scott \& White, the Veterans Administration (VA) Research Scholar Award, and a VA Merit Award (G.A.); D.A. was supported by Italian Ministry of Education, University and Research (MUIR) grants: PRIN\#2007 and prot. 2007HPT7BA_003. E.G. was supported by MIUR grants: PRIN\#2007, prot. 2007HPT7BA_001, and Federate Atheneaum funds from the University "Sapienza" of Rome.

A.F. and A.T. contributed equally to this work.

Accepted for publication June 10, 2010.

Supplemental material for this article can be found on http://ajp. amjpathol.org

Address reprint requests to Domenico Alvaro, M.D., via R. Rossellini 51, Division of Gastroenterology, Department of Clinical Medicine, University of Rome "Sapienza," 00137 Rome, Italy. E-mail: domenico.alvaro@uniroma1.it. 
apy. ${ }^{1-3}$ CCA arises from the neoplastic transformation of cholangiocytes, the epithelial cells lining the biliary tree. Although important advances have been obtained in the last few years, the mechanisms leading to neoplastic transformation, growth, and spreading of CCA cells are undefined. ${ }^{4,5}$ As in other cancers, dysregulation of multiple mechanisms modulating cell proliferation and apoptosis have been described in CCA. 1,2,4,5 Unfortunately, a progressive increase in incidence and mortality for CCA has been reported worldwide, which mainly affect the intrahepatic form of CCA. ${ }^{3,6}$ Half of CCA are not candidate for surgical resection at the time of diagnosis $^{1-3}$ and no efficacious treatment exists. Therefore, research aimed to find a new therapeutic target is currently an important challenge.

Prostate apoptosis response-4 (Par-4), a tumor suppressor protein that sensitizes cells to apoptotic stimuli, ${ }^{6-16}$ was first identified in prostate cancer cells that were induced to undergo apoptosis. Par-4 is a leucine zipper domain protein widely expressed in diverse normal and cancerous cell types and tissues and resides in both the cytoplasm and the nucleus. Endogenous PAR-4 itself does not cause apoptosis, yet it is essential for apoptosis induced by a variety of exogenous insults. ${ }^{6-16}$ Recent studies suggest how Par-4 serves as an intracellular repressor of topoisomerase 1 catalytic activity, and regulates DNA topology to suppress cellular transformation. ${ }^{7,8}$ Consistent with its tumor suppressor function, Par-4 is silenced or mutated in different types of cancers, ${ }^{11-13}$ and experimental models of Par-4 knockout spontaneously develop tumors in various organs. ${ }^{17}$ In contrast, transgenic mice overexpressing Par-4 showed resistance to development of spontaneous and oncogene-induced, autochthonous tumors. ${ }^{18}$ Therefore, Par-4 modulation has tremendous therapeutic potential and, indeed, genetic or pharmacological strategies to induce Par-4 expression are currently under investigation for cancer prevention or treatment. ${ }^{9,19-21}$ To this regard, it is noteworthy that different natural compounds inducing Par-4 expression have been identified and proposed for cancer chemoprevention. ${ }^{19-21}$ No data exist on the role of Par-4 in modulating cholangiocyte proliferation and apoptosis, and the expression of Par-4 in human CCA is unknown. The aim of our study was to evaluate the expression of Par-4 in normal and neoplastic cholangiocytes and the effects of its pharmacological or genetic modulation on cell proliferation and apoptosis. Our findings demonstrate how Par-4 is involved in modulating apoptosis in CCA, suggesting Par-4 as a new potential therapeutic target for this devastating cancer.

\section{Materials and Methods}

Reagents were purchased from Sigma Chemical Co (St. Louis, MO) unless otherwise indicated. HuH-28 cell line derived from intrahepatic CCA was acquired from Cancer Cell Repository, Tohoku University (Sendai, Japan) and maintained in CRML 1066 medium containing 10\% fetal bovine serum (FBS). TFK-1 cell line (derived from extra-hepatic CCA) was kindly provided by Dr. Yoshiyuki
Ueno form Cancer Cell Repository, Tohoku University, and maintained in RPMI medium containing 10\% FBS. The hepatocellular carcinoma HepG2 cell line was acquired from Sigma Chemical Co and maintained in minimal essential medium (BioConcept's AMIMED, Switzerland) containing 10\% FBS, 1\% NEAA, 1\% Na-pyruvate, and $1 \%$ L-glutamine. 3,3'-diindolylmethane (B-DIM) was obtained from BioResponse (Boulder, CO). Withaferin A (WA), a major constituent of the medicinal plant Withania somnifera, was obtained from Chromadex (Santa Ana, CA). Media and additives for cell culture were obtained from Gibco (BRL, Invitrogen Corporation s.r.I., S. Giuliano Milanese, Italy) unless otherwise indicated.

\section{Human Liver Samples}

The use of human material has been approved by the local Institutional Review Board. Samples of CCA and/or liver were obtained from (1) 10 patients (five female patients, aged 64 to 73 years, and five male patients, aged 67 to 75 years) with intrahepatic CCA presenting as a single mass lesion within the liver and submitted to surgical resection; (2) seven patients affected by extra-hepatic CCA (Klatskin tumor), (three female patients, aged 69 to 77 years, and four male patients, aged 68 to 78 years) submitted to radical surgery; and (3) five biopsies from liver donors with a normal histology (three female patients and two male patients, aged 49 to 54 years).

\section{Light Microscopy and Immunohistochemistry}

Liver fragments $(0.5 \mathrm{~cm})$ were fixed in $10 \%$ buffered formalin for 2 to 4 hours, embedded in low-temperaturefusion paraffin $\left(55^{\circ} \mathrm{C}\right.$ to $\left.57^{\circ} \mathrm{C}\right)$ : 3 - to $4-\mu \mathrm{m}$ sections were stained with hematoxylin-eosin and Masson's trichrome. For immunohistochemistry (IHC), sections were mounted on glass slides coated with $0.1 \%$ poly-L-lysine. After deparaffination, endogenous peroxidase activity was blocked by a 30-minute incubation in methanolic hydrogen peroxide (2.5\%). The endogen biotin was then blocked by Biotin Blocking System (Dako, code X0590, Dako, Copenhagen, Denmark) according to the instructions supplied by the vendor. Sections were hydrated in graded alcohol and rinsed in PBS ( $\mathrm{pH}$ 7.4) before applying the primary antibody. Sections were incubated overnight at $4^{\circ} \mathrm{C}$ with antibodies for (1) Par-4 (Santa Cruz, Inc., Santa Cruz, CA; sc-1666, mouse monoclonal; 1:100); (2) tumor suppressor phosphatase and tensin homolog deleted in chromosome 10 (PTEN; Dako, M3627; mouse monoclonal; 1:20); (3) proliferating cellular nuclear antigen (PCNA; Dako, PC10; mouse monoclonal; 1:100); (4) bcl-2-associated X protein (BAX; Santa Cruz, Inc., sc-7480, mouse monoclonal; 1:200); (5) B cell lymphoma gene-2 (pBCL2; Santa Cruz, Inc., sc-7382, mouse monoclonal; 1:100); and (6) nuclear factor- $\mathrm{B}$ (pNFкB; Santa Cruz, Inc., sc-33039-R, rabbit polyclonal; 1:50). Samples were then rinsed with PBS for 5 minutes, incubated for 20 minutes at room temperature with secondary biotinylated antibody (Dako LSAB Plus System, HRP, Milan, Italy), then with Dako ABC (Dako LSAB Plus 
System, HRP) and finally developed with 3-3' diaminobenzidine. For all immunoreactions, negative controls (the primary antibody was replaced with pre-immune serum) were also included. Light microscopy and IHC observation were taken by Olympus BX-5 1 Light Microscopy (Tokyo, Japan) with a Videocam (Spot Insight, Diagnostic Instrument, Inc., Sterling Heights, MI) and processed with an Image Analysis System (IAS-Delta Sistemi, Rome, Italy). Light microscopy and IHC observations were independently performed by three pathologists in a blind fashion. Briefly, six slides were analyzed per each specimen of normal liver or CCA. Neoplastic or normal cholangiocytes were counted in a random, blinded fashion in six nonoverlapping fields (magnification $\times 20$ ) of each slide and the data expressed as percent positive cells.

\section{Isolated Bile Duct Units from Human Liver}

Fragments of intrahepatic bile ducts, averaging $20 \mu \mathrm{m}$ in diameter, were isolated from human liver (five liver donors, 1 Gram pieces) as previously described for isolation and characterization of bile duct units from rat liver. ${ }^{22}$

\section{Cell Cultures}

$\mathrm{HuH}-28$ or TFK-1 cells were platted on six-well plates and maintained in appropriate medium supplemented with $10 \%$ FBS, $100 \mathrm{U} / \mathrm{ml}$ penicillin, $100 \mathrm{mg} / \mathrm{ml}$ streptomycin, in humidified atmosphere of $5 \% \mathrm{CO}_{2}$.

$\mathrm{HuH}-28$ or TFK- 1 cells were exposed to $17 \beta$-estradiol, insulin-like growth factor 1 (IGF1), Withaferin A or B-DIM, and proliferation or apoptosis evaluated as follows. $17 \beta$ estradiol, Withaferin A, and B-DIM were prepared as stock solutions in dimethyl sulfoxide (DMSO) while IGF1 was dissolved in saline. $17 \beta$-estradiol stock solutions were then diluted $(1: 1,000,000)$, Withaferin A or B-DIM stock solutions were diluted $(1: 10,000)$, and IGF1 stock solutions were then diluted 1:10,000 into serum-free culture medium. Control cells were exposed to DMSO or saline only.

\section{Proliferation and Apoptosis}

Cell proliferation was assessed as described ${ }^{23,24}$ by both 3-(4,5-dimethylthiazol-2-yl)-5-(3-carboxymethoxyphenyl)2-(4-sulfophenyl)-2H-tetrazolium (MTS) proliferation assay and PCNA protein expression (Western blot). For MTS proliferation assay, we used a commercially available colorimetric cell proliferation assay (Cell Titer 96 AQueous NonRadioactive Cell Proliferation Assay, MTS Kit, Promega, Madison, WI), by following the manufacturer's instructions. Proliferation index was calculated as the ratio (multiplied $x$ 100) between cell numbers in unstimulated and stimulated cultures.

Apoptosis was induced in cell lines by different maneuvers including serum depletion for 48 hours, exposure to human recombinant TRAIL (tumor necrosis factorrelated apoptosis-inducing ligand), or to beauvericin. TRAIL was dissolved in PBS (10 $\mu \mathrm{g} / \mathrm{ml}$ stock solution), stored at $-20^{\circ} \mathrm{C}$ in multiple aliquots, and then added (1:1000, $100 \mathrm{ng} / \mathrm{ml}$ ) for 24 hours into HuH-28 cell cultured in the appropriate medium containing 10\% FBS. Beauvericin was dissolved in methanol $(3 \mathrm{mmol} / \mathrm{L}$ stock solution), stored at $-20^{\circ} \mathrm{C}$ in multiple aliquots, and then added (1:10,000; $25 \mu \mathrm{mol} / \mathrm{L})$ for 8 hours in $\mathrm{HuH}-28$ cells cultured in the appropriate medium containing $10 \%$ FBS. Control cells were incubated in a medium containing an equivalent amount of methanol for 8 hours.

Apoptosis was evaluated ${ }^{23,24}$ by measuring caspase- 3 and -8 activity. For caspase-3, we used a colorimetric assay kit (Sigma-Aldrich), based on the hydrolysis of the peptide substrate acetyl-Asp-Glu-Val-Asp p-nitroanilide (Ac-DEVD$\mathrm{pNA}$ ) by caspase-3, resulting in the release of the $p$-nitroanilide ( $p-N A)$. For this assay, cells were lysed in the appropriate lysis buffer provided by the vendor $(50 \mathrm{mmol} / \mathrm{L}$ HEPES, pH 7.4, 5 mmol/L 3-[(3-cholamidopropyl)dimethylammonio]-1-propanesulfonate (CHAPS), and $5 \mathrm{mmol} / \mathrm{L}$ DTT). The spectrophotometric absorbance of each sample, calculated at $405 \mathrm{~nm}$, was normalized with its protein content and expressed as caspase-3 activity in relative absorbance intensity. For caspase-8, we used a colorimetric assay kit (Sigma-Aldrich), based on the hydrolysis of the peptide substrate acetyl-lle-Glu-Thr-Asp p-nitroaniline by caspase 8 , resulting in the release of the $\mathrm{p}-\mathrm{NA}$. For this assay, cells were lysed in the appropriate lysis buffer provided by the vendor ( $50 \mathrm{mmol} / \mathrm{L}$ HEPES, $\mathrm{pH} 7.4,5 \mathrm{mmol} / \mathrm{L}$ CHAPS, and $5 \mathrm{mmol} / \mathrm{L}$ DTT). The spectrophotometric absorbance of each sample, calculated at $405 \mathrm{~nm}$, was normalized with its protein content and expressed as caspase-8 activity in relative absorbance intensity.

\section{Quantitative RT-PCR}

Pieces of dissected tissues (about $30 \mathrm{mg}$ ) were immediately submerged in RNAlater stabilization solution (Ambion, Inc., Austin, TX). Each sample was left 10 minutes at room temperature and then stored at $-20^{\circ} \mathrm{C}$ until being submitted to RNA extraction. The tissue fragment removed from RNAlater was transferred into a clean Eppendorf tube where the total RNA was extracted by using the TRI REAGENT (Sigma-Aldrich) and 1-bromo-3-chloropropane by following the manufacturer's instructions. The isolated RNA was dissolved in $55 \mu$ l of RNase-free water. RNA quality and quantity was evaluated by the RNA 6000 Nano LabChip kit with the Agilent 2100 Bioanalyzer (Agilent Technologies, Waldbronn, Germany) as previously described. ${ }^{25}$

An amount of $2.5 \mu \mathrm{g}$ of total RNA was used for the RT reaction primed by the random hexamer (Invitrogen). This was conducted in a $20-\mu$ l volume with a genetically engineered version of the M-MuLV reverse transcriptase (Expand Reverse Trancriptase, Roche Diagnostics $\mathrm{GmbH}$, Mannheim, Germany) according the manufacturer's directions. The quality of cDNA produced, ie, the length of the transcript and the lack of DNA contamination, was tested by PCR with the RNA/cDNA Inspector kit (Sigma-Aldrich) and the DNA1000 LabChip kit with the Agilent 2100 BioAnalyzer as we previously described. ${ }^{26}$

Gene expression was determined by real-time PCR with a MX3000P instrument (Stratagene, La Jolla, CA) by 
Table 1. Sequences of Primers Used for Amplifying or Silencing the PAR-4 Gene

Sequences of primer pairs (sense and antisense, respectively) used for amplifying PAWR or PAR-4 and three internal contro genes used for the geometric averaging normalization procedure (HPRT1, HMBS, and GAPDH)

\begin{tabular}{|c|c|c|c|c|}
\hline Gene & Primer sequence & Length (nt) & Product (bp) & Origin \\
\hline PAWR & $\begin{array}{l}\text { 5'-AGGGATGCAAATGTTTCAGG-3' } \\
\text { 5'-TCACAAGTCTTAGGTTTTCTTGTCTT-3' }\end{array}$ & $\begin{array}{l}20 \\
23\end{array}$ & 112 & 1 \\
\hline HPRT1 & $\begin{array}{l}5^{\prime}-\text { TGACACTGGCAAAACAATGC-3' } \\
5^{\prime}-\text { GGTCCTTTTCACCAGCAAGCT-3' }\end{array}$ & $\begin{array}{l}20 \\
21\end{array}$ & 99 & 2 \\
\hline$H M B$ & $\begin{array}{l}5^{\prime} \text {-GGCAATGCGGCTGCAA- } 3^{\prime} \\
5^{\prime}-\text { GGGTACCCACGCGAATCAC-3' }\end{array}$ & $\begin{array}{l}16 \\
19\end{array}$ & 72 & 2 \\
\hline GAPDH & $\begin{array}{l}5^{\prime}-\text { AGCCACATCGCTCAGACAC }-3^{\prime} \\
5^{\prime}-\text { GCCCAATACGACCAAATCC }-3^{\prime}\end{array}$ & $\begin{array}{l}19 \\
19\end{array}$ & 66 & 1 \\
\hline
\end{tabular}

1. Primers designed by PROBEFINDER software (Exiqon A/S, Vedbaek, Denmark). 2. Primers according to Lee et al. ${ }^{6}$

Sequences of Primer Pairs (Sense and Antisense, respectively) Used for Silencing PAR-4

\begin{tabular}{ccc}
\hline Gene & Primer sequence & Length (nt) \\
\hline PAWRHSS107599 & 5'-UCCCUAGAUAUAACAGGGAUGCAAA-3' & 25 \\
PAWRHSS107600 & 5'-UUUGCAUCCCUGUUAUAUCUAGGGA-3' & 25 \\
& 5'-ACUUGUGAGACUGAUGCAAGAUAAA-3' & 25 \\
PAWRHSS181749 & 5'-UUUAUCUUGCAUCAGUCUCACAAGU-3' & 25 \\
& 5'-GCGGAAACGAGAAGAUGCAAUUACA-3' & 25 \\
\hline
\end{tabular}

using the averaged cycle threshold (Ct) automatically computed by the built-in software from three replicas of each sample. PCR amplifications were conducted into a volume of $25 \mu \mathrm{l}$, with $1.0 \mu \mathrm{l}$ of CDNA template, $12.5 \mu \mathrm{l}$ of 2× SYBR Green Brilliant QPCR Master Mix (Stratagene), 3 pmoles each of upstream and downstream primer for the gene analyzed, and $0.3 \mu$ l of diluted reference dye (6-Carboxyl-X-Rhodamine $[R O X]$ at a final concentration $30 \mathrm{nmol} / \mathrm{L})$. All real-time PCR amplifications were conducted with the following cycling program: 10 minutes at $95^{\circ} \mathrm{C}$ followed by 40 cycles (30 seconds at $95^{\circ} \mathrm{C}, 30$ seconds at $60^{\circ} \mathrm{C}$, and 30 seconds at $72^{\circ} \mathrm{C}$ ). The fluorescence detection was performed during the extension step of each cycle.

The expression of the gene of interest, ie, the PRKC Apoptosis WT1 Regulator (PAWR), was normalized by three endogenous reference genes, ie, hypoxanthine phosphoribosyl-transferase I (HPRT1), hydroxymethyl-bilane synthase (HMBS), and glyceraldehyde-3-phosphate dehydrogenase (GAPDH), as suggested. ${ }^{6}$ The sequences of primers used are as reported in Table 1.

The normalization factors calculated from internal control genes using the geometric averaging described by Vandesompele et $\mathrm{al}^{27}$ allowed us to evidence small relative differences of the PAWR gene expression in the various samples by the accurate ranking of gene of interest determinations.

\section{Western Blot}

As previously described, ${ }^{23,24}$ cells were harvested, washed with PBS, and whole cell lysate was prepared by suspending the cells in added 100 to $150 \mu$ of radioimmunoprecipitation assay buffer (Sigma) with $1 \mathrm{mmol} / \mathrm{L}$ phenylmethylsulfonyl fluoride, $2 \mu \mathrm{g} / \mathrm{ml}$ aprotinin on ice for 10 to 15 minutes. Protein concentration was determined with the Bio-Rad Protein Assay-Dye Reagent (Bio-Rad
Laboratories GmbH, Germany). For immunoblotting, each extract was prepared as described above, and 30 $\mu \mathrm{g}$ total protein was separated through SDS-polyacrylamide gel electrophoresis, electrotransferred onto nitrocellulose membranes, and probed with the following: anti-Par-4 mouse monoclonal, anti-PCNA mouse monoclonal (Santa Cruz Biotechnology), and anti- $\beta$-actin mouse monoclonal antibody (Sigma Chemical Co.). Detection of specific proteins was carried out with an enhanced chemiluminescence Western blotting kit (Qdot Western blotting kit, Invitrogen).

\section{Small-Interfering RNA}

The following duplexed RNA oligonucleotides (Stealth RNAi) were synthesized by Invitrogen (Table 1). As a control, we used Stealth RNAi negative control duplexes (Invitrogen). The effectiveness of the RNAi experiments in our experimental conditions was confirmed by using Stealth RNAi GAPDH positive control duplexes (Invitrogen), according to the manufacturer's instructions.

$\mathrm{HuH}-28$ cells were cultured in 12-well plates and used at $50 \%$ to $70 \%$ density the day of transfection. Cells were transfected with Lipofectamine RNAiMAX (Invitrogen) according to the manufacturer's instruction.

Following small-interfering RNAs (siRNAs) treatment (72 hours), HuH-28 cells were harvested and assessed for total Par-4 content by Western blotting with anti Par-4 mouse monoclonal antibodies (Santa Cruz Biotechnology), and proliferation and apoptosis were studied by Western blotting for PCNA protein expression, MTS-assay, and Caspase3-activity assay.

\section{Statistical Analysis}

Data are presented as arithmetic mean \pm SD. Statistical analysis was conducted by using the paired or unpaired 


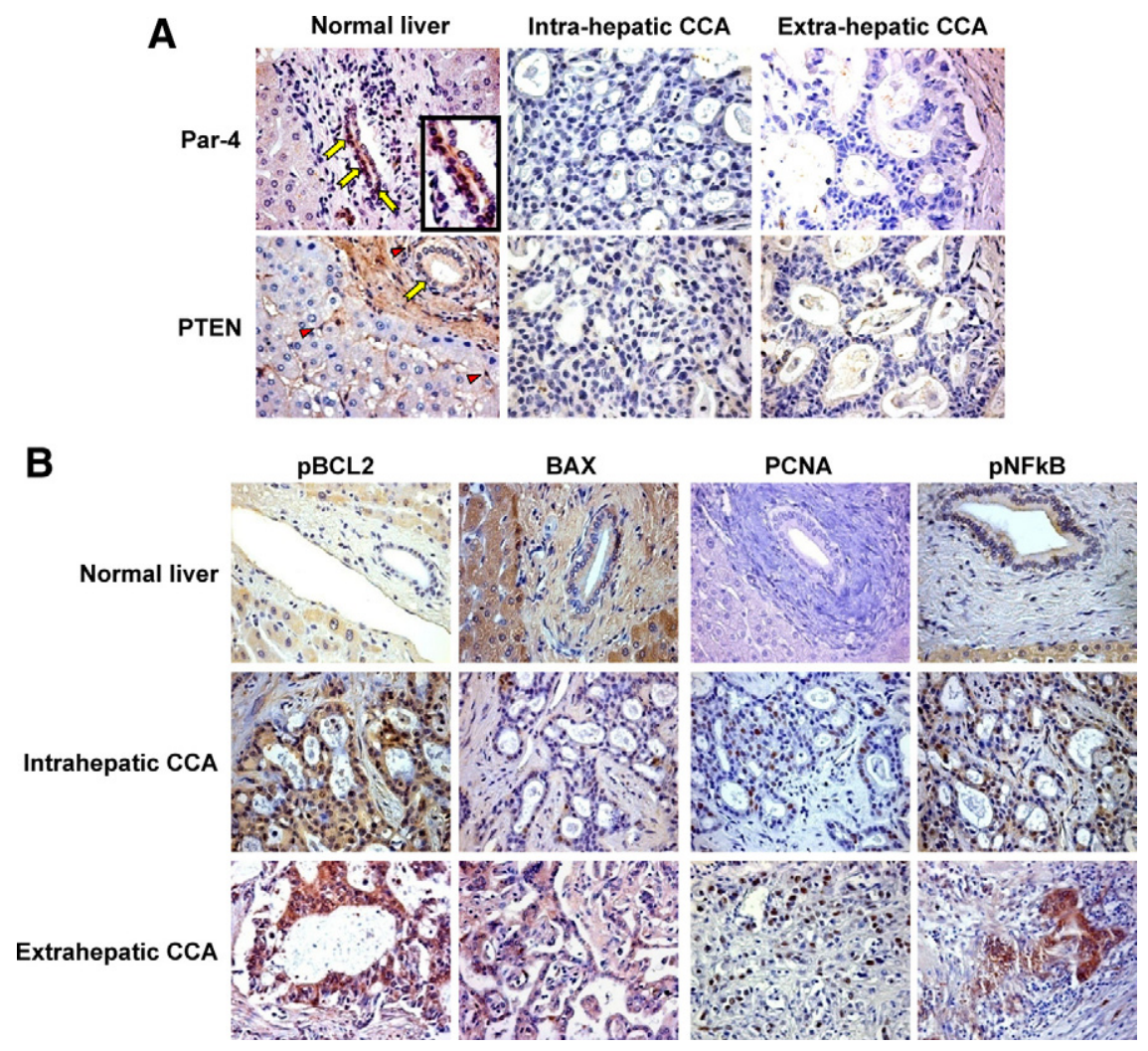

Figure 1. IHC expression of Par-4, PTEN, pBCL2, BAX, PCNA, and pNF $\kappa$ B in normal human liver, intrahepatic CCA, and extrahepatic CCA. A: Par- 4 and PTEN. In normal livers, Par- 4 was expressed by cholangiocytes (yellow arrows) and few hepatocytes; the inset shows (at higher magnification) the nuclear and cytoplasmatic expression of Par- 4 in cholangiocytes of normal liver. In CCA samples, Par-4 expression is reduced, and neoplastic cells were mostly negative. In normal livers, PTEN was expressed by portal myofibroblasts and hepatic stellate cells (red arrowheads) and by cholangiocytes (yellow arrows). In CCA samples, both neoplastic cells and stromal cells were mostly PTENnegative. Representative of five normal livers, 10 intrahepatic CCA, and seven extrahepatic CCA Original magnification, $\times 40$. B: pBCL2, BAX PCNA, and pNF $\kappa$ B. BAX expression was decreased in both intrahepatic and extrahepatic CCA with respect to cholangiocytes of normal liver. The IHC expression levels of PCNA, pBCL2, and $\mathrm{pNF} \kappa \mathrm{B}$ were increased in both intrahepatic and extrahepatic CCA with respect to normal cholangiocytes. Representative of five normal livers, 10 intrahepatic CCA, and seven extrahepatic CCA. Original magnification, $\times 40$.

Student's $t$-test as appropriate or the analysis of the variance when multiple comparisons were performed. A $P$ value $<0.05$ was considered statistically significant. Correlations between variables were performed by using the Spearman's correlation coefficient.

\section{Results}

\section{Par-4 IHC Expression in Human Liver and CCA}

In the $\mathrm{IHC}$, Par-4 was expressed in the normal human liver by both hepatocytes and cholangiocytes. The staining pattern is located at both cytoplasmic and nuclear level (Figure 1A). Par-4 was also expressed by intrahepatic and extra-hepatic CCA, but the percentage of positive cancer cells was markedly decreased in comparison with the percentage of positive cholangiocytes in normal livers $(P<0.05$; Table 2$)$. Moreover, 4/10 intrahepatic and 3/7 extra-hepatic CCA were virtually negative for Par-4 expression ( $<5 \%$ of tumoral cells positive).

Par-4 is currently considered an important player in the PTEN network. Phosphorylation of Par-4 by Akt, the latter controlled by PTEN, allows the chaperone 14-3-3 to bind and sequester Par-4 in the cytoplasm. Conversely, inactivation of Akt induces Par-4-dependent apoptosis. ${ }^{10,11} \mathrm{Si}$ multaneous inactivation of PTEN and Par-4 leads PI3K/Akt and $\mathrm{NF}-\kappa \mathrm{B}$ pathways to be activated and to offer complementary advantage to cells to progress toward an invasive phenotype. $^{10}$ When evaluated by IHC, PTEN was expressed by hepatic stellate cells within the liver lobule, by portal myofibroblasts and, in particular, by myofibroblasts encircling bile ducts (Figure 1A). Moreover, cholangiocytes in interlobular bile ducts as well as hepatocytes were immunoreactive for PTEN. In intrahepatic and extra-hepatic CCA, PTEN expression in neoplastic cells was significantly lower in comparison with the percentage of positive cholan-

Table 2. Immunohistochemistry in Normal Liver and CCA Samples

\begin{tabular}{lcrr}
\hline $\begin{array}{c}\text { Markers of apoptosis } \\
\text { or proliferation }\end{array}$ & $\begin{array}{c}\text { Normal human liver } \\
\text { (\% positive cholangiocytes) }\end{array}$ & $\begin{array}{c}\text { Intrahepatic CCA } \\
\text { (\% positive tumor cells) }\end{array}$ & $\begin{array}{c}\text { Extrahepatic CCA } \\
\text { (\% positive tumor cells) }\end{array}$ \\
\hline Par-4 & $24.60 \pm 3.96$ & $8.80 \pm 1.98^{*}$ & $12.14 \pm 3.23^{*}$ \\
PTEN & $33.80 \pm 3.61$ & $9.60 \pm 2.69^{*}$ & $5.57 \pm 1.27^{*}$ \\
BAX & $32.00 \pm 5.15$ & $8.30 \pm 1.48^{*}$ & $12.29 \pm 2.60^{*}$ \\
PBCL-2 & $23.80 \pm 3.34$ & $50.30 \pm 4.03^{*}$ & $45.00 \pm 3.78^{*}$ \\
BAX/pBCL2 & $1.50 \pm 0.32$ & $0.19 \pm 0.05^{*}$ & $0.31 \pm 0.08^{*}$ \\
PCNA & $12.40 \pm 1.12$ & $25.90 \pm 2.15^{*}$ & $27.43 \pm 2.71^{*}$ \\
PNF $\kappa$ B & $15.00 \pm 1.58$ & $23.80 \pm 2.73^{*}$ & $27.14 \pm 4.21^{*}$ \\
\hline
\end{tabular}

Mean \pm SD of five normal livers, 10 intrahepatic CCA, and seven extrahepatic CCA.

${ }^{\star} P<0.05$ versus normal human liver. 
giocytes in normal livers $(P<0.05$; Table 2; Figure $1 \mathrm{~A})$. In addition, in CCA specimens, stromal cells surrounding the tumor cells were mostly PTEN negative. Moreover, 2/10 intrahepatic and 3/7 extra-hepatic cholangiocarcinoma samples were virtually negative for PTEN expression $(<5 \%$ of tumoral cell positive). All PTEN negative CCA specimens were simultaneously Par-4 negative.

The expression of the anti-apoptotic protein $\mathrm{pBCL2}$ (Figure 1B; Table 2) was higher in intrahepatic and extrahepatic CCA compared with cholangiocytes of normal livers $(P<0.05)$. In contrast, the expression of the proapoptotic protein BAX was lower (Figure 1B, Table 2; $P<$ $0.05)$ in CCA cells in comparison with normal cholangiocytes. Moreover, in intrahepatic and extra-hepatic CCA samples, the BAX/pBCL2 ratio (Table 2), a parameter of apoptosis, ${ }^{25}$ was directly correlated with Par-4 expression $(r=0.79 ; P<0.01)$.

The nuclear expression of PCNA, a marker of proliferation, ${ }^{28}$ and of NF- $\kappa \mathrm{B}$, which activates anti-apoptotic/pro survival genes and is inhibited during Par-4 mediated apoptosis, ${ }^{11}$ were higher in intrahepatic and extra-hepatic-CCA compared with cholangiocytes of normal livers $(P<0.05$; Figure 1B; Table 2$)$ and was inversely correlated with the expression of Par-4 (PCNA: $r=-0.80, P<$ 0.05; pNF $\kappa$ B: $r=-0.81, P<0.05)$.

These findings altogether indicate that Par-4 was down-regulated in either intrahepatic and extra-hepatic CCA, where it was directly correlated with markers of apoptosis (BAX, BAX/pBCL2 ratio) and inversely correlated with markers indicative of activated proliferation (PCNA, pNF $\kappa$ B) and inhibited apoptosis (pBCL2).

\section{Quantitative RT-PCR Analysis of Par-4 in Human Intrahepatic CCA}

By quantitative RT-PCR, the message for PAR-4 was compared between peri-tumoral areas and cancerous areas selected from surgically resected intrahepatic CCA. The cancerous and noncancerous nature of selected fragments was confirmed by normal histology. The cancerous areas showed significantly lower amounts of Par-4 mRNA (ie, the ratio of copy numbers Par4/GAPDH) relative to peri-tumoral areas (Figure $2 \mathrm{~A} ; n=6, P<0.05$ ). These findings were also confirmed when Par-4 mRNA was normalized for other two internal reference genes, HPRT1 and HMBS (not shown).

\section{Expression of Par-4 (Immunoblotting) in CCA Cell Lines and Its Change During Cell Proliferation}

Par-4 expression was analyzed by Western blot in the $\mathrm{HuH}-28$ cell line (derived from human intrahepatic CCA), in the TFK-1 cell line (derived from extra-hepatic CCA), and in the hepatocarcinoma cell line HepG2. Human bile duct units isolated from liver donors and total human liver fragments were used for comparison. The CCA cell lines, $\mathrm{HuH}-28$ and TFK-1, showed significantly lower levels of Par-4 protein expression in comparison with either normal
A

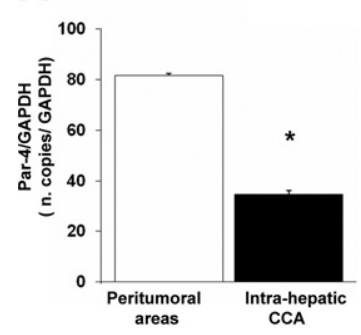

B

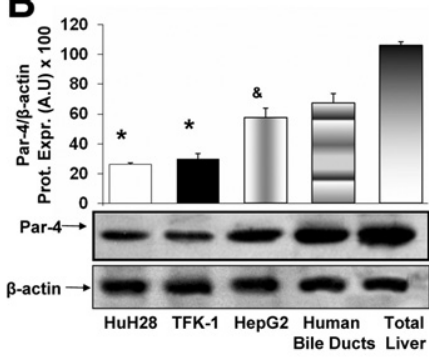

C

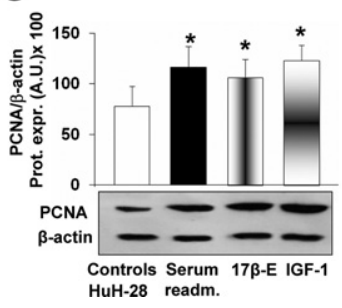

D

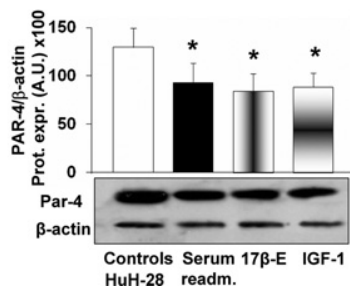

Figure 2. Expression of Par- 4 in human intrahepatic CCA and the HuH-28 cell line and its change after cell proliferation. A: Quantitative RT-PCR analysis of Par-4 in human intrahepatic CCA. Par-4 mRNA was compared between peritumoral areas and cancerous areas (CCA) selected from surgically resected intrahepatic CCA. Par- 4 was normalized to GAPDH as the reference gene (ie, the ratio of copy numbers Par- $4 /$ GAPDH). Par- 4 mRNA was significantly decreased in intrahepatic CCA with respect to peritumoral areas. Data represent the mean $\pm \mathrm{SD}$ of six independent experiments. ${ }^{*} P<$ 0.05 . B: Immunoblotting of Par-4 in HuH-28, TFK-1, HepG2 cells, human bile duct units, and total human liver. Human bile duct units were prepared according to the procedures described in Materials and Methods. The Par- 4 protein was expressed (Prot. Expr.) as A.U. normalized to $\beta$-actin expression (ie, tested protein $/ \beta$-actin $\times 100$ ). Par- 4 protein expression was significantly lower in CCA cell lines, HuH-28 and TFK-1, with respect to human bile duct units or fragments obtained from human liver (liver donors). Par-4 protein expression was significantly lower in the hepatocarcinoma cell line, HepG2, with respect to total liver fragments. Data represent the mean \pm SD of four independent experiments. ${ }^{*} P<0.05$ versus other columns; ${ }^{*} P<0.05$ versus total liver. $\mathbf{C}$ and D: Changes in PCNA and Par- 4 protein expression during HuH-28 cell proliferation. HuH-28 cells, cultured in the appropriate medium containing $10 \%$ fetal bovine serum, were deprived of serum for 24 hours. Then cells were maintained in serum-deprived conditions for an additional 12 hours (controls) or exposed to serum, $17 \beta$-estradiol $(17 \beta$-E; $10 \mathrm{nmol} / \mathrm{L}$ ), and IGF1 $(1.3 \mathrm{nmol} / \mathrm{L})$ for 12 hours (see Materials and Methods). PCNA (C) and Par-4 (D) were expressed (Prot. Expr.) as A.U. normalized to $\beta$-actin expression (ie, tested protein $/ \beta$-actin $\times 100$ ). Serum readmission, $17 \beta$-E, and IGF1 induced increased PCNA protein expression, indicative of stimulated proliferation, in association with a significant decrease in Par-4 protein expression. Data represent the mean \pm SD of five independent experiments. ${ }^{*} P<0.05$ versus controls.

human bile duct units or total human liver (Figure 2B; $n=$ 4, $P<0.05)$. Par-4 was also expressed by the hepatocarcinoma cell line HepG2 at a significantly lower level with respect to total human liver fragments (Figure 2B; $n=4, P<0.05)$. These findings indicate that Par-4 is expressed, although down-regulated, in CCA cell lines.

To evaluate the relationships between Par-4 protein expression and cell proliferation, CCA cell lines, $\mathrm{HuH}-28$ and TFK-1 cells, were induced to proliferate by exposure to serum (after serum-depletion), $17 \beta$-estradiol, or IGF1. Specifically, HuH-28 and TFK-1 cells starved without serum for 24 hours were left without serum (controls) or exposed to serum, $17 \beta$-estradiol, or IGF1 for an additional 12-hour period. Serum-readmission induced a significant increase $(\mathrm{HuH}-28=+49 \pm 19 \%$; TFK-1 $=+$ $51 \pm 14 \% ; n=5, P<0.05)$ of PCNA protein expression (Western blot; Figure 2C and supplemental Figure 1A, see http://ajp.amjpathol.org) and a decrease $(\mathrm{HuH}-28=$ 
$-46 \pm 4 \%$; TFK-1 $=-52 \pm 8 \% ; n=4, P<0.05$, not shown) of caspase 3 activity (apoptosis) with respect to controls. In these experiments, in association with proliferation induced by serum-readmission, a $28 \pm 19 \%$ (HuH-28, $n=5, P<0.05)$ and a $27 \pm 12 \%$ (TFK-1, $n=$ $5, P<0.05)$ decrease of Par-4 protein expression with respect to controls was observed (Figure 2D and supplemental Figure 1B, see http://ajp.amjpathol.org). Similar findings were observed when serum-deprived (24 hours) $\mathrm{HuH}-28$ and TFKI-1 cells were induced to proliferate by exposure to $10 \mathrm{nmol} / \mathrm{L} 17 \beta$-estradiol or $1.3 \mathrm{nmol} / \mathrm{L}$ IGF1. As previously described, ${ }^{23,24,28} 17 \beta$-estradiol and IGF1 induced a significant increase of PCNA protein expression $(\mathrm{HuH}-28=+36 \pm 15 \%$ for $17 \beta$-estradiol and + $58 \pm 14 \%$ for IGF1; TFK-1 $=+40 \pm 12 \%$ for $17 \beta-$ estradiol and $+40 \pm 11 \%$ for IGF1; $n=5, P<0.05$ versus controls; Figure $2 \mathrm{C}$ and supplemental Figure 1A, see $h$ ttp://ajp.amjpathol.org) and a significant decrease of apoptosis (caspase 3 activity: $17 \beta$-estradiol: $\mathrm{HuH}-28=$ $-48 \pm 5.1 \%$; TFK-1 $=-44 \pm 4 \%$; IGF1: HuH-28 $=$ $-47 \pm 4 \%$; TFK $-1=-50 \pm 6 \% ; n=5, P<0.05$ versus controls, not shown). In association with induced proliferation, Par-4 protein expression (Western blot) was found to be decreased in $\mathrm{HuH}-28$ cells by $34 \pm 18 \%$ and $31 \pm 14 \%(n=5, P<0.05)$, respectively, by $17 \beta-$ estradiol or IGF1 with respect to controls (Figure 2D). In TFK-1 cells, Par-4 protein expression was found to be decreased by $28 \pm 15 \%$ and $28 \pm 14 \%(n=5, P<0.05$; supplemental Figure 1B, see http://ajp.amjpathol.org), respectively, by $17 \beta$-estradiol or IGF1 with respect to controls. These findings indicate that in CCA cell lines, cell proliferation is associated with decreased expression of Par-4.

\section{Changes of PAR-4 Expression during Apoptosis of CCA Cell Lines}

Par-4 protein has been shown to function as effector of cell death in response to various apoptotic stimuli that trigger mitochondria and membrane receptor-mediated cell death pathways. ${ }^{10,29}$ To investigate the relationships between Par-4 protein expression and apoptosis of CCA cells, we evaluated different apoptotic stimuli, including serum depletion or exposure to beauvericin or TRAIL.

As previously described, ${ }^{23,24,28} \mathrm{HuH}-28$ cells cultured in media containing $10 \%$ bovine serum were depleted of serum (ie, exposed to serum-free medium) for 48 hours. After 48 hours of serum-depletion, the activities of caspase-3 ( $+48 \pm 6 \%$ versus controls, $n=6$, Figure $3 \mathrm{~A})$ and caspase- 8 ( $+55 \pm 3 \%$ versus controls, $n=6$, Figure 3B) were significantly $(P<0.03)$ increased in $\mathrm{HuH}-28$ cells and this was associated with enhanced BAX protein expression ( $+38 \pm 2 \%$ versus controls, $n=6$, Figure $3 \mathrm{C})$. In these experiments, in association with apoptosis induced by serum depletion, the protein expression of Par-4 was significantly increased $(+49 \pm 9.8 \%$ versus controls, Figure 3D; $n=6, P<0.05$ ).

Beuavericin induces apoptosis by multiple cellular/molecular pathways. ${ }^{30}$ After exposure of $\mathrm{HuH}-28$ cells to 25 $\mu \mathrm{mol} / \mathrm{L}$ beauvericin for 8 hours, caspase-3 activity increased by $74 \pm 4 \%$ versus controls (Figure $3 \mathrm{E}, n=5$,
$P<0.02)$ and caspase-8 activity increased from $2.85 \pm$ 0.15 (controls) to $5.28 \pm 0.20$ (spectrophotometric absorbance at $405 \mathrm{~nm}$, arbitrary densitometric units [A.U.]; $n=$ $5, P<0.05)$ confirming effective apoptosis, and this was associated with a significant increase $(+76 \pm 10 \%$ versus controls, Figure $3 F ; n=5, P<0.05$ ) of Par-4 protein expression.

Finally, selective activation of extrinsic pathway of apoptosis by TRAIL ${ }^{31}$ induced a $43 \pm 5 \%$ increase of caspase-3 activity $(P<0.05$ versus controls, Figure 3G; $n=4$ ) and caspase-8 activity (from $2.80 \pm 0.16$ in controls to $8.67 \pm 0.92$ spectrophotometric absorbance at $405 \mathrm{~nm}$, A.U.; $n=4 ; P<0.01)$ in association with a significant increase of Par-4 protein expression (+65 \pm $9 \%$ versus controls, Figure $3 \mathrm{H} ; n=4, P<0.05$ ).

Results obtained with $\mathrm{HuH}-28$ cells were also confirmed in the extra-hepatic CCA cell line, TFK-1. In fact, in TFK -1 cells depleted of serum for 48 hours, the activity of caspase-3 $(+70 \pm 4 \%$ versus controls, $n=4, P<0.05$; supplemental Figure 2A, see $h$ ttp://ajp.amjpathol.org) was increased and this was associated with a significant increase of Par- 4 protein expression $(+64 \pm 4 \%$ versus controls, $n=4, P<0.05$; supplemental Figure 2B, see http://ajp.amjpathol.org).

Together, these findings indicate that Par- 4 protein expression increases during apoptosis of CCA cell lines induced by different stimuli.

\section{Effect of Selective Par-4 Silencing on Proliferation and Apoptosis of HuH-28 Cells}

To evaluate the effects of decreased Par-4 intracellular levels on proliferation and apoptosis, $\mathrm{HuH}-28$ cells were incubated for 72 hours with specific Par-4 siRNA or control (scrambled) RNA. We tested three different sequences of Stealth RNAi kit, synthesized by Invitrogen. The PAWRHSS107600 sequence induced a $50 \pm 2.6 \%$ decrease of Par-4 protein expression compared with the cells transfected with the control siRNA (Stealth RNAi Negative Control duplexes; Figure $4 \mathrm{~A} ; n=4, P<0.02$ ). The other two tested sequences (PAWRHSS107599 and PAWRHSS181749) induced respectively a $37 \pm 3.9 \%$ and $28 \pm 7.1 \%$ decrease of Par- 4 protein expression compared with the cells transfected with the control siRNA ( $n=4$, Stealth RNAi Negative Control duplexes; data not shown). On the basis of these findings, we therefore evaluated the effect of Par-4 silencing by PAWRHSS107600 siRNA sequence on proliferation and apoptosis of $\mathrm{HuH}-28$ cells. As positive control, we used Stealth RNAi GAPDH positive control duplexes (Invitrogen), according to the manufacturer's instructions. In association with the decreased intracellular Par-4 levels, HuH-28 cells selectively silenced for Par-4 showed a significant increase in PCNA protein expression (Western blot), indicative of induced cell proliferation (Figure 4B). In fact, PCNA protein expression was significantly increased $(+46.8 \pm 4.2 \%)$ in $\mathrm{HuH}-28$ silenced cells with respect to control siRNA (Figure $4 \mathrm{~B} ; n=4, P<0.02$ ). These data were confirmed by MTS-assay. In fact, treatment with Par-4 siRNA induced a marked increase 
A

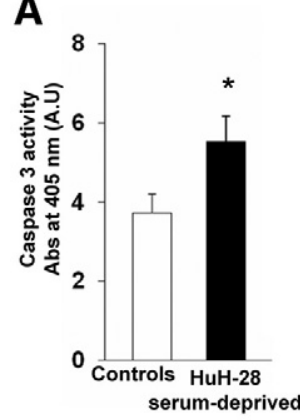

E

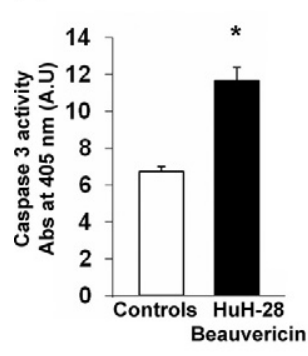

B

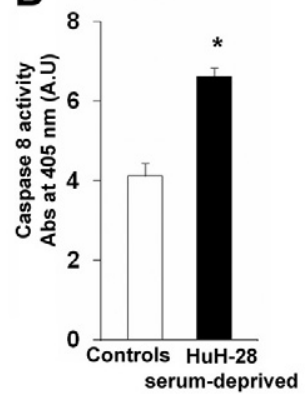

F

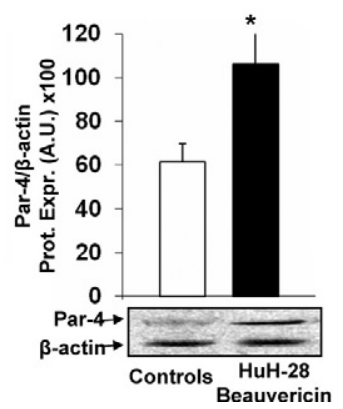

C

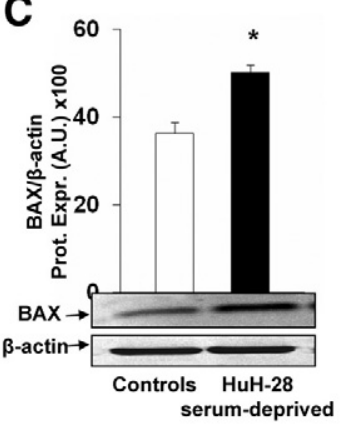

G

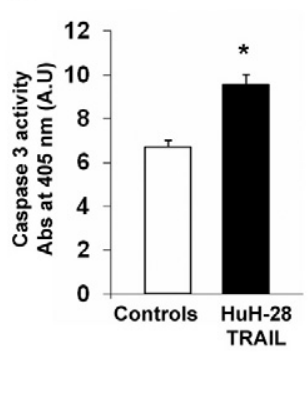

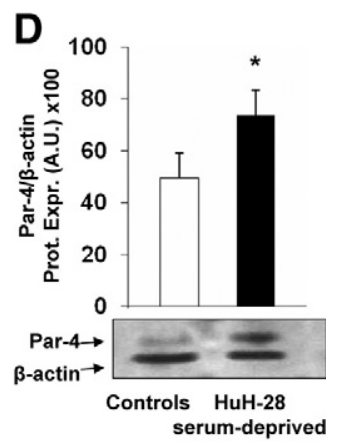

H

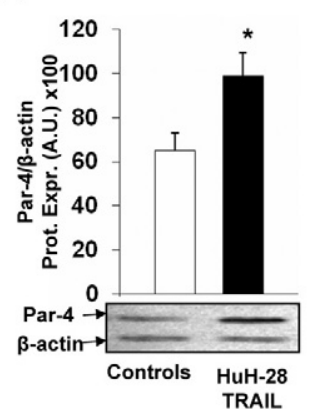

Figure 3. PAR-4 protein expression during apoptosis of HuH-28 cells induced by serum depletion, beauvericin, or TRAIL. A and B: Effect of serum depletion on caspase-3 (A) and caspase-8 (B) activity in HuH-28 cells. HuH-28 cells cultured in appropriate medium containing $10 \%$ fetal bovine serum were depleted of serum for 48 hours and compared with cells maintained in $10 \%$ serum for the same time. Apoptosis was evaluated by measuring caspase- 3 and caspase- 8 activities. Caspase-3 was evaluated by the hydrolysis of Ac-DEVD-pNA with the release of p-NA. Caspase- 8 was evaluated by the hydrolysis of the peptide substrate acetyl-lle-Glu-Thr-Asp p-nitroaniline, resulting in the release of p-NA. Caspase-3 or -8 activity resulted from the measured concentration of p-NA (spectrophotometric absorbance at $405 \mathrm{~nm}$ ) normalized for protein concentration. Serum depletion induced a significant increase in caspase-3 and - 8 activity. Data represent the mean \pm SD of six independent experiments. ${ }^{*} P<0.02$ versus controls. C and D: Effect of serum depletion on BAX (C) and Par- 4 (D) expression (Western blot) in HuH-28 cells. HuH-28 cells cultured in appropriate medium containing $10 \%$ fetal bovine serum were depleted of serum for 48 hours and compared with cells maintained in 10\% serum for the same time (controls). BAX and Par-4 protein were expressed (Prot. Expr.) as A.U. normalized to $\beta$-actin expression (ie, tested protein $/ \beta$-actin, $\times 100)$. Serum depletion induced a significant increase in BAX $(\mathbf{C})$ and Par- 4 (D) protein expression. Data represent the mean \pm SD of six independent experiments. ${ }^{*} P<0.05$ versus controls. E and F: Effect of beuavericin on caspase-3 and Par- 4 expression in HuH-28 cells. HuH-28 cells were exposed to $25 \mu \mathrm{mol} / \mathrm{L}$ beuavericin for 8 hours and caspase-3 activity (E) (apoptosis) and Par-4 protein expression (F) were evaluated with respect to controls incubated with the carrier DMSO. In HuH-28 cells treated with beuavericin, caspase-3 activity was increased in association with enhanced Par- 4 expression. Data represent the mean \pm SD of five independent experiments. ${ }^{*} P<0.05$ versus controls. G and $\mathbf{H}$ : Effect of TRAIL on caspase-3 and Par- 4 expression in HuH-28 cells. HuH-28 cells were incubated with TRAIL for 24 hours, and caspase-3 activity (G) (apoptosis) and Par-4 protein expression (H) were evaluated with respect to controls. In HuH-28 cells treated with TRAIL, caspase-3 activity was increased in association with enhanced Par- 4 expression. Data represent the mean \pm SD of four independent experiments. ${ }^{*} P<0.05$ versus controls.

$(+58.3 \pm 11.5 \%)$ of proliferation index (Figure $4 \mathrm{C} ; n=6$, $P<0.05$ ) with respect to controls. As far as apoptosis is concerned, 72-hour incubation with siRNA for Par-4 induced a decrease of caspase 3 activity ( $-43 \pm 3.3 \%)$ with respect to controls (Figure 4D; $n=4, P<0.05$ ), indicative of apoptosis inhibition.

Findings obtained in the intrahepatic CCA cell line $\mathrm{HuH}-28$ were also confirmed in the extra-hepatic CCA cell line, TFK-1. As shown in supplemental Figure 3A (see http:// ajp.amjpathol.org), Par-4 silencing by PAWRHSS107600 siRNA sequence in TFK-1 cells induced a $37 \pm 8 \%$ decrease of Par-4 protein expression compared with the TFK-1 cells transfected with the control siRNA (Stealth RNAi Negative Control duplexes; $n=4, P<0.05$ ). In association with the decreased intracellular Par-4 levels, TFK-1 cells selectively silenced for Par-4 showed a significant increase in PCNA protein expression $(+32 \pm 6 \%$ versus control siRNA, $n=4, P<0.05$; supplemental Figure 3B, see http://ajp.amjpathol.org) and of proliferation index (+39 \pm $3 \% ; n=4, P<0.05$ versus control siRNA; supplemental Figure 3C, see http://ajp.amjpathol.org), indicating activation of cell proliferation. Consistently, 72-hour incubation of TFK-1 cells with siRNA for Par-4 induced a decrease of caspase 3 activity $(-30 \pm 2 \%$ ) with respect to controls ( $n=$ 4,P<0.05; supplemental Figure 3D, see http://ajp.amjpathol. org), indicative of apoptosis inhibition.

Altogether, these data confirmed that down-regulation of Par-4 intracellular levels activate proliferation and inhibits apoptosis of CCA cell lines, $\mathrm{HuH}-28$ and TFK-1.

\section{Effect of Par-4 Pharmacological Induction on Proliferation and Apoptosis of CCA Cell Lines, $\mathrm{HuH}-28$ and TFK-1}

As recently described for different cancer cells, WA or B-DIM are two natural compounds capable of inducing Par-4 expression. ${ }^{19,20,32}$ Given the therapeutic implications, we evaluated the effects of WA and B-DIM on Par-4 expression and proliferation or apoptosis of CCA cell line. $\mathrm{HuH}-28$ cells cultured in media added with $10 \%$ bovine serum were exposed to WA (4 $4 \mathrm{~mol})$ for 24 hours while controls cells were incubated with DMSO only as WA carrier. After treatment of $\mathrm{HuH}-28$ cells with WA, Par-4 levels were increased by $31.6 \pm 10.4 \%$ (Figure $5 A ; n=5$, $P<0.05)$, PCNA protein expression decreased by $21 \pm$ 
A
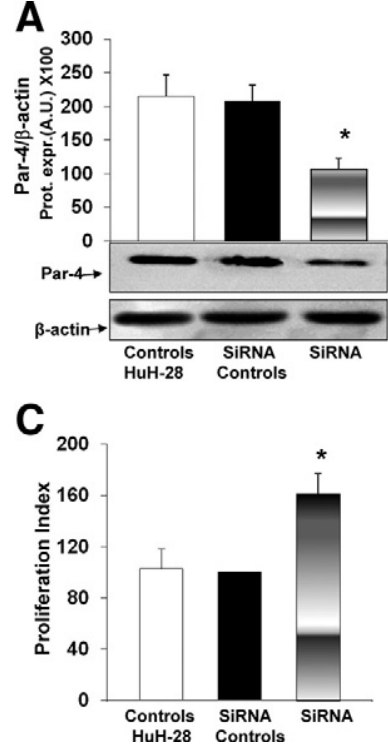

B

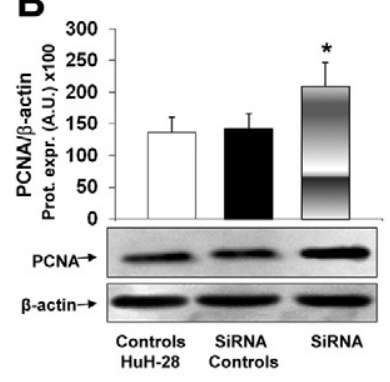

D 160

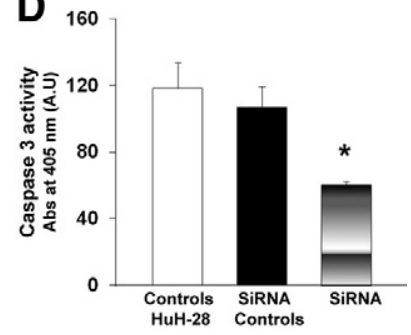

Figure 4. Effect of Par-4 selective silencing on proliferation and apoptosis of HuH-28 cells. A and B: Par- 4 and PCNA protein expression (Western blot) in HuH-28 cells treated with siRNA. HuH-28 cells were incubated with Par-4specific siRNA, scrambled RNA (siRNA controls), or untreated (controls) in 12 -well culture plates containing the appropriate medium plus $10 \%$ fetal bovine serum for 72 hours. Par- 4 (A) and PCNA (B) were expressed (Prot. Expr.) as A.U. normalized to $\beta$-actin expression (ie, tested protein $/ \beta$-actin $\times$ 100). Par-4-specific siRNA induced a significant decrease in Par-4 protein expression in association with increased PCNA. Data represent the mean \pm $\mathrm{SD}$ of four independent experiments. ${ }^{*} P<0.02$ versus controls. C: MTS proliferation assay. Under the same experimental conditions described in $\mathbf{A}$ and $\mathbf{B}$, the MTS assay was performed to evaluate cell proliferation. Absorbance values were measured at $490 \mathrm{~nm}$ after cells were incubated with $20 \mu \mathrm{l}$ MTS reagent for 2 hours (see Materials and Methods). Absorbance values were measured at $490 \mathrm{~nm}$. The proliferation index was calculated as the ratio (multiplied $\times 100$ ) between cell number (MTS assay) in treated and untreated (control) cultures. Data represent the mean $\pm \mathrm{SD}$ of six independent experiments. ${ }^{*} P<0.005$ versus controls. D: Caspase- 3 activity. Under the same experimental conditions described in $\mathbf{A}$ and $\mathbf{B}$, caspase- 3 activity was measured to evaluate apoptosis. Caspase- 3 was measured by the hydrolysis of Ac-DEVD-pNA with the release of p-NA. Caspase-3 activity resulted from the measured concentration of p-NA (spectrophotometric absorbance at $405 \mathrm{~nm}$ ) normalized for protein concentration. Data represent the mean \pm SD of four independent experiments. ${ }^{*} P<0.005$ versus controls.

2.5\% (Figure 5B; $n=5, P<0.05$ ), MTS proliferation index inhibited by $20 \pm 1.6 \%$ (Figure $5 \mathrm{C} ; n=6, P<0.05$ ), and caspase 3 activity was increased by $49 \pm 10 \%$ (Figure $5 \mathrm{D} ; n=5, P<0.02)$, with respect to controls.

Similar results were obtained with TFK-1 cells. Treatment of TFK- 1 cells with WA ( $4 \mu \mathrm{mol})$ for 24 hours, in fact, induced a $38 \pm 4 \%$ increase of Par-4 protein expression ( $n=5, P<0.05$ versus DMSO controls; supplemental Figure 4A, see http://ajp.amjpathol.org) in association with decreased PCNA expression $(-25 \pm 2 \%, n=5, P<0.05$ versus DMSO controls; supplemental Figure 4B, see http:// ajp.amjpathol.org) and MTS proliferation index $(-55.62 \pm$ $7 \% ; n=6, P<0.05$ versus DMSO controls; supplemental Figure 4C, see $h$ ttp://ajp.amjpathol.org), whereas caspase 3 activity was increased by $57 \pm 9 \%(n=5, P<0.02$ versus DMSO controls; supplemental Figure 4D, see http://ajp.amjpathol.org).

At the same experimental conditions, similar findings were obtained with B-DIM. In fact, $10 \mu \mathrm{mol} / \mathrm{L}$ B-DIM induced significant increase $(+35 \pm 3.4 \%)$ of Par-4 levels in $\mathrm{HuH}-28$ cells (Figure $6 \mathrm{~A} ; n=7, P<0.05$ ) in association with decreased $(-22 \pm 7.1 \%)$ PCNA protein expression (Western blot, Figure 6B; $n=5, P<0.05$ ), lower

A

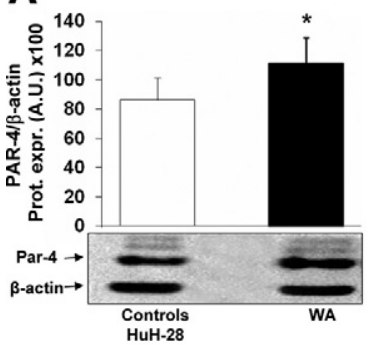

B
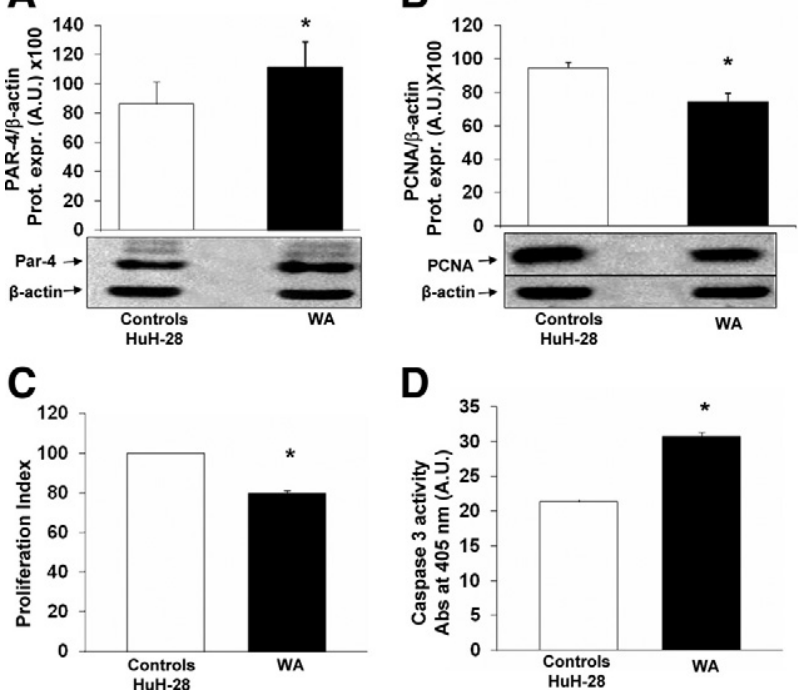

Figure 5. Effect of WA on proliferation and apoptosis of HuH-28 cells and Par-4 expression. A and B: Effect of WA on the protein expression levels of Par-4 (A) and PCNA (B) in HuH-28 cells. HuH-28 cells cultured in the appropriate medium containing 10\% FBS were maintained in $10 \%$ fetal bovine serum + DMSO (WA carrier) for an additional 24 hours (controls) or exposed to WA $(4 \mu \mathrm{mol} / \mathrm{L})$ for the same time. The Par- 4 and PCNA proteins were expressed (Prot. Expr.) as A.U. normalized to $\beta$-actin (ie, tested protein/ $\beta$-actin $\times 100$ ). WA induced a significant increase in Par-4 protein expression in association with decreased PCNA levels. Data represent the mean \pm SD of five to seven independent experiments. ${ }^{*} P<0.05$ versus controls. C: MTS proliferation assay. Under the same experimental conditions described in $\mathbf{A}$ and $\mathbf{B}$, the MTS assay was performed to evaluate cell proliferation. The proliferation index was calculated as the ratio (multiplied $\times 100$ ) between cell number (MTS assay) in treated and untreated (control) cultures. Data represent the mean $\pm \mathrm{SD}$ of six independent experiments. ${ }^{*} P<0.005$ versus controls. D: Caspase-3 activity. Under the same experimental conditions described in $\mathbf{A}$ and $\mathbf{B}$, WA induced a significant increase in apoptosis evaluated as caspase- 3 activity. Caspase- 3 activity was measured by the hydrolysis of Ac-DEVD-pNA with the release of p-NA. The concentration of p-NA (spectrophotometric absorbance at $405 \mathrm{~nm} \times 10$ ) was normalized for protein concentration. Data represent the mean $\pm \mathrm{SD}$ of five independent experiments. ${ }^{*} P<0.02$ versus controls.

MTS proliferation index $(-25 \pm 4.7 \%$; Figure $6 \mathrm{C} ; n=5$, $P<0.02)$, and increase of caspase 3 activity $(+31 \pm$ $3.4 \%$; Figure $6 \mathrm{D} ; n=4, P<0.05)$ in comparison with controls. With respect to $10 \mu \mathrm{mol} / \mathrm{L}$ B-DIM, $20 \mu \mathrm{mol} / \mathrm{L}$ B-DIM showed similar effects.

These findings indicate that the natural compounds, WA and DIM, induce in CCA cell lines Par-4 expression in association with inhibition of proliferation and activation of apoptosis.

\section{Discussion}

The main findings of this study indicate that (1) Par-4 is expressed in normal cholangiocytes and is down-regulated in human CCA and CCA cell lines (HuH-28 and TFK-1); (2) Par-4 protein expression is decreased during proliferation of CCA cell lines induced by different stimuli (serum, estrogens, and IGF1), whereas it is increased during apoptosis induced by different stimuli (serum depletion, beauvericin, and TRAIL); (3) Par-4 selective silencing by specific siRNA induced proliferation and inhibited apoptosis of CCA cell lines; and (4) pharmacological agents inducing Par-4 activate apoptosis and inhibit proliferation of CCA cell lines. Altogether these find- 
A

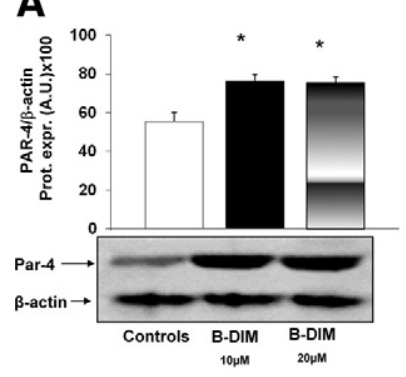

C

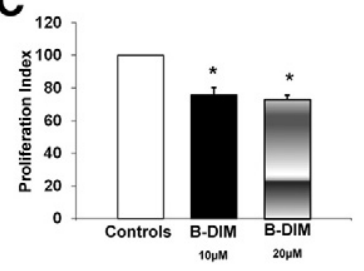

B

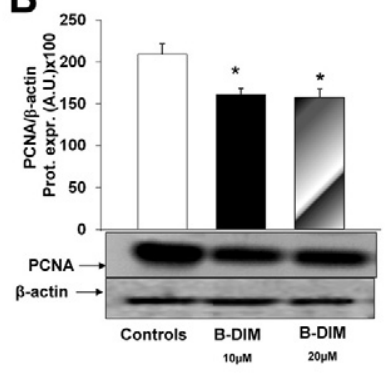

D

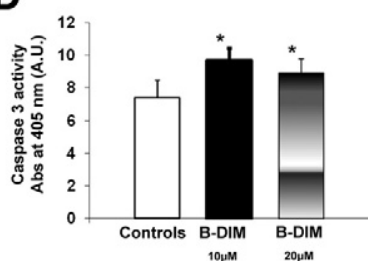

Figure 6. Effect of B-DIM on proliferation, apoptosis of HuH-28 cells, and Par-4 expression. A and B: Effect of B-DIM on the protein expression levels of Par-4 (A) and PCNA (B) in HuH-28 cells. HuH-28 cells cultured in the appropriate medium containing 10\% FBS were maintained in $10 \%$ FBS + DMSO (B-DIM carrier) for an additional 24 hours (controls) or exposed to B-DIM (10 or $20 \mu \mathrm{mol} / \mathrm{L})$ for the same period. The Par- 4 and PCNA proteins were expressed (Prot. Expr.) as A.U. normalized to $\beta$-actin (ie, tested protein/ $\beta$-actin $\times 100$ ). B-DIM induced a significant increase in Par-4 protein expression in association with decreased PCNA levels. No differences were found between 10 or $20 \mu \mathrm{mol} / \mathrm{L}$ B-DIM. Data represent the mean $\pm \mathrm{SD}$ of five to seven independent experiments. ${ }^{*} P<0.05$ versus controls. C: MTS proliferation assay. Under the same experimental conditions described in $\mathbf{A}$ and $\mathbf{B}$ the MTS assay was performed to evaluate cell proliferation. The proliferation index was calculated as the ratio (multiplied $\times 100$ ) between cell number (MTS assay) in treated and untreated (control) cultures. B-DIM (10 or 20 $\mu \mathrm{mol} / \mathrm{L}$ ) induced a significant increase in the proliferation index. Data represent the mean $\pm \mathrm{SD}$ of five independent experiments. ${ }^{*} P<0.02$ versus controls. D: Caspase-3 activity. Under the same experimental conditions described in $\mathbf{A}$ and $\mathbf{B}$, B-DIM (10 or $20 \mu \mathrm{mol} / \mathrm{L})$ induced a significant increase in apoptosis evaluated as caspase- 3 activity. Caspase- 3 activity was measured by the hydrolysis of Ac-DEVD-pNA with the release of p-NA. The concentration of $\mathrm{p}$-NA (spectrophotometric absorbance at $405 \mathrm{~nm} \times 10$ ) was normalized for protein concentration. Data represent the mean $\pm \mathrm{SD}$ of four independent experiments. ${ }^{*} P<0.05$ versus controls.

ings indicate that Par-4 plays a major role in modulating proliferation and apoptosis of CCA cells.

Par-4, a tumor suppressor protein showing pro-apoptotic functions, has been shown to function as an effector of cell death in response to various apoptotic stimuli that trigger mitochondria and membrane receptor-mediated cell death pathway. ${ }^{10-16,29}$ Epigenetic silencing of Par-4 has been described in different tumors, and Par-4 knockout mice develop spontaneous tumors in various tissues. ${ }^{11-13,17,18}$ At experimental level, it has been shown that endogenous Par-4 sensitizes cells to diverse apoptotic stimuli and that ectopic expression of Par-4 can selectively induce apoptosis in cancer cells. ${ }^{14-18}$ The cancer-specific pro-apoptotic action of Par-4 resides in its centrally located SAC (selective for apoptosis in cancer cells) domain where SAC transgenic mice display normal development and life span, and, most importantly, are resistant to spontaneous, as well as oncogene-induced autochthonous tumors. ${ }^{18}$ As far as mechanism of apoptosis induction is concerned, in rat fibroblasts it has been recently demonstrated that Par-4 binds its interaction partner DAPlike kinase (DIk/ZIP kinase) and induces translocation of the kinase from the nucleus to the actin filaments, with subsequent myosin light chain phosphorylation and induction of

apoptosis. ${ }^{10,13,29,33,34}$ More recently, it was noted that Par-4 protein is spontaneously secreted by normal and cancer cells in culture as well as by tissues from transgenic mice overexpressing Par-4 and showing resistance to spontaneous tumors. ${ }^{13}$ In the same study, exposure to endoplasmic reticulum stress-inducing agents further increased cellular secretion of Par-4, where extracellular Par-4 induced apoptosis by binding to the stress response surface protein, glucose-regulated protein-78. ${ }^{13}$ The interaction of extracellular Par-4 with glucose-regulated protein-78 leads to apoptosis via endoplasmic reticulum (ER) stress and activation of the Fas-associated death domain protein (FADD)/ caspase-8/caspase-3 pathway. Also TRAIL inducible apoptosis was found to be dependent from extracellular Par-4 signaling via cell surface glucose-regulated protein-78. ${ }^{13}$ In the last few years, Par-4 received large attention as a therapeutic target since different pharmacological agents induced Par-4 and showed, at the experimental levels, anticancer effects. ${ }^{19-21,32}$ Most importantly, natural compounds able to induce Par-4 expression have been identified and proposed for cancer chemoprevention with the hypothesis that they should be able to suppress, reverse, or prevent the carcinogenic process from turning into aggressive cancer. ${ }^{19-21}$

CCA is a devastating cancer with frustrating response to chemotherapeutics. ${ }^{1-5}$ In this study we focus on the expression of Par-4 in normal and neoplastic cholangiocytes and on the role of Par-4 in the modulation of proliferation and apoptosis of CCA cells.

Par-4 expression was investigated by $\mathrm{IHC}$ in small fragments of intrahepatic CCA and peritumoral tissues obtained from patients submitted to surgical resection. In these samples, the presence of CCA and its absence in peritumoral areas was demonstrated by normal histology. The IHC analysis showed Par-4 expression at the cytoplasmic and nuclear levels. Although nuclear Par-4 represents the most active form, different studies demonstrated that Par-4 may be active, in regulating cell proliferation/apoptosis, also in the cytoplasm where it may act on specific PKC isoforms, which in turn may influence the activity of both $N F-\kappa B$ (via IKK) and AKT. ${ }^{35,36}$ However, it is of interest that in normal cholangiocytes Par-4 staining was also found in the nucleus suggesting a potential role in maintaining these cells into a quiescent status. Most importantly, we showed how Par-4 IHC expression was markedly down-regulated in intrahepatic CCA cells in comparison with both peritumoral areas and cholangiocytes of normal liver. Consistent with IHC findings, we also demonstrated by RT-PCR that the message for Par-4 is decreased by 2.5 -fold in intrahepatic CCA with respect to peri-tumoral areas, and these findings were confirmed by normalizing RT-PCR results with three different reference proteins. Par-4 expression is also decreased in extra-hepatic CCA, and in our samples, Par-4 staining results directly correlated with the markers of apoptosis, BAX and BAX/BCL2 ratio, ${ }^{28}$ and was inversely correlated with direct (PCNA) or indirect $(\mathrm{NF}-\kappa \mathrm{B})$ markers of proliferation. ${ }^{28}$ These findings are suggestive that also in CCA, as occurs in other cancers, Par-4 is strongly involved in the positive modulation of apoptotic machineries. In addition, the $\mathrm{IHC}$ investiga- 
tion showed how the decreased Par-4 expression in CCA was closely associated with decreased positivity for PTEN, both being correlated with increased indices of proliferation (bcl2 staining) and decreased indices of apoptosis (Bax staining). This is in keeping with what demonstrated in human prostatic cancer where Par-4 loss is concomitantly associated with PTEN loss. ${ }^{7,8}$ In experimental models, Par-4 null mice or PTEN-heterozygous mice only develop benign lesions while only concomitant Par-4 ablation and PTENheterozygosity lead to invasive prostate cancer in mice, the tumorigenic Par-4/PTEN cooperation being anticipated in the preneoplastic prostate epithelium by an additive increase in Akt and NF- $\kappa \mathrm{B}$ activation. ${ }^{11}$ Furthermore, Par-4 deficiency cooperates with PTEN haploinsufficiency in prostate cancer initiation and progression and their simultaneous inactivation, in addition to enhancing Akt activation, causes the synergistic activation of NF- $\kappa$ B. PTEN expression has been demonstrated to be decreased in extrahepatic CCA and to correlate with worst survival, ${ }^{37}$ and intrahepatic CCA has been experimentally induced by liverspecific disruption of Smad4 and PTEN in mice. ${ }^{38}$ Therefore, impairment of PTEN pro-apoptotic functions certainly plays a role in CCA pathogenesis. Our IHC findings in human CCA samples suggest, as shown in other cancers, ${ }^{10}$ a close relationship between PTEN and Par-4 downregulation and CCA cell proliferation.

We next investigated, in functional studies, in two different CCA cell lines, derived from intrahepatic (ie, $\mathrm{HuH}$ 28) or extra-hepatic (ie, TFK-1) human CCA, the expression of Par-4 and its relationships with cell proliferation and apoptosis. The two CCA cell lines showed lower levels of Par-4 protein expression with respect to total liver and intrahepatic bile ducts. A hepatocarcinoma cell line, HepG2, also showed Par-4 expression at lower level with respect to total liver indicating that, in the liver, Par-4 is not exclusively involved in modulating cholangiocyte but also hepatocyte pathophysiology. As far as functional studies are concerned, we demonstrated that when CCA cell lines were induced to proliferate by serum-readmission or exposure to IGF1 or $17 \beta$-estradiol, in all these conditions, a significant decrease of Par-4 expression was observed. As far as apoptosis is concerned, Par- 4 is currently considered an effector of cell death in response to various apoptotic stimuli that trigger mitochondria and membrane receptor-mediated cell death pathways. ${ }^{29}$ Therefore, we investigated apoptosis of CCA cell lines induced by serum depletion, beuavericin, and by TRAIL, the latter being a selective activator of extrinsic apoptotic pathways. ${ }^{31}$ With all these different apoptotic stimuli, Par-4 protein expression was up-regulated in association with enhanced caspase-3 and -8 activities, respectively terminator and initiator of the apoptotic cascade, and with enhanced expression of the pro-apoptotic protein BAX. This latter finding is consistent with the $\mathrm{IHC}$ results obtained in human CCA biopsies and showing a positive correlation between BAX and Par-4 staining. Therefore, the results of functional studies confirmed the role of Par-4 in CCA cells as pro-apoptotic and anti-proliferative protein documented in other different cell types. This was definitively confirmed by selective Par-4 silencing, which induced proliferation of HuH-28 and TKF-1 cells. In these latter experiments, a 50\% decrease of Par-4 protein level determined a $58 \%$ increase of proliferation index.

Given the relevance of Par-4 in controlling apoptotic pathways, a bulk of recent literature deals with pharmacological or genetic induction of Par-4 expression as anti-cancer strategy. ${ }^{19-21}$ Specific attention was given to cancer chemoprevention, which focuses on natural, synthetic, or biological agents capable to suppress, reverse, or prevent the carcinogenic process from turning into aggressive cancer. We tested in HuH-28 and/or TFK-1 cells, two natural compounds (WA and B-DIM) with therapeutic potential against cancer and minimal toxicity against normal cells and which have been described as inducers of Par-4. ${ }^{19,20}$ WA, a highly oxygenated C-28 ergostane-type steroid, is a major constituent of the medicinal plant $W$. somnifera, identified as natural agent with therapeutic potential against cancer and preferably minimal toxicity against normal cells. ${ }^{19,39,40}$ The growth-inhibitory properties in tumor cell culture studies have been largely documented with the evidence that its action is dependent on Par-4 function in both androgen-responsive and androgen refractory prostate cancer cells. ${ }^{19,39,40}$ Our results indicate that WA induces apoptosis and inhibit proliferation of CCA cell lines, HuH-28 and TFK-1, and this is in association with an increased expression of Par-4, increased caspase-3 activity, and decreased PCNA expression. The same effect was found with BDIM, tested only in HuH-28 cells, which is another natural compound found in cruciferous vegetables, recently described as one of the most effective phytonutrients with potential in the prevention and treatment of breast, prostate, colon, and pancreatic cancers. ${ }^{20,21}$ We tested two different doses of B-DIM without differences in Par-4 induction, which, in addition, was of the similar entity with respect to the induction obtained with WA. In a previous study, ${ }^{32}$ DIM has been shown to promote Fas-mediated apoptosis of CCA cell lines by inhibiting phosphorylation of AKT and activation of FLICE (Fas-associated death domain-like interleukin-1beta-converting enzyme) like-inhibitory-protein, FLIP. In keeping with previous studies, ${ }^{20,21}$ our findings indicate that Par-4 induction is an additional mechanism involved in B-DIM induced apoptosis of CCA cells, where PTEN (AKT antagonist) could also be taken into consideration. We demonstrated that WA and B-DIM impair proliferation and induce apoptosis of $\mathrm{HuH}-28$ cells without affecting viability of normal cholangiocytes, thus excluding toxicity for normal cells.

Cancer chemoprevention is defined as the use of natural, synthetic, or biological agents to suppress, reverse, or prevent the carcinogenic process from turning into aggressive cancer. A number of pathological conditions are at risk of CCA development including primary sclerosing cholangitis (PSC), liver flukes, surgical bilio-enteric anastomosis, etc. ${ }^{1-}$ 5,41 For all these categories at risk, no chemoprevention strategy has been so far investigated. Our findings showing the major role of Par-4 as modulator of apoptosis should stimulate clinical trials aimed to evaluate the role of natural compounds inducing Par-4 as chemotherapeutic agents preventing CCA developments. Finally, since no chemotherapy has been demonstrated to be of great benefit in CCA treatment at this time, drugs or 
genetic strategies selectively targeting Par-4 should be investigated.

\section{References}

1. Blechacz B, Gores GJ: Cholangiocarcinoma: advances in pathogenesis, diagnosis, and treatment. Hepatology 2008, 48(1):308-321

2. Khan SA, Thomas HC, Davidson BR, Taylor-Robinson SD: Cholangiocarcinoma. Lancet 2005, 366(9493):1303-1314

3. Patel T: Worldwide trends in mortality from biliary tract malignancies. BMC Cancer 2002, 2:10

4. Fava G, Marzioni M, Benedetti A, Glaser S, DeMorrow S, Francis H, Alpini G: Molecular pathology of biliary tract cancers. Cancer Lett 2007, 250(2):155-167

5. Alvaro D, Mancino MG: New insights on the molecular and cell biology of human cholangiopathies. Mol Aspects Med 2008, 29(1-2):50-57

6. Alvaro D, Crocetti E, Ferretti S, Bragazzi MC, Capocaccia R; the AISF "Cholangiocarcinoma" Committee. Descriptive epidemiology of cholangiocarcinoma in Italy. Dig Liver Dis 2009, Dec 18. [Epub ahead of print]

7. Sells SF, Wood DP, Joshi-Barve SS, Muthukumar S, Jacob RJ, Crist SA, Humphreys S, Rangnekar VM: Commonality of the gene programs induced by effectors of apoptosis in androgen-dependent and -independent prostate cells. Cell Growth Differ 1994, 5:457-466

8. Goswami A, Quu S, Dexheimer TS, Ranganathan P, Burikhanov R, Pommier Y, Rangnekar VM: Par-4 binds to topoisomerase 1 and attenuates its DNA relaxation activity. Cancer Res 2008, 68:1-9

9. Lee TJ, Lee JT, Kim SH, Choi YH, Song KS, Park JW, Kwon TK: Overexpression of Par-4 enhances thapsigargin-induced apoptosis via down-regulation of XIAP and inactivation of Akt in human renal cancer cells. J Cell Biochem 2008, 103(2):358-368

10. Diaz-Meco MT, Abu-Baker S: The Par-4/PTEN connection in tumor suppression. Cell Cycle 2009, 8(16):2518-2522

11. Fernandez-Marcos PJ, Abu-Baker S, Joshi J, Galvez A, Castilla EA, Cañamero M, Collado M, Saez C, Moreno-Bueno G, Palacios J, Leitges M, Serrano M, Moscat J, Diaz-Meco MT: Simultaneous inactivation of Par-4 and PTEN in vivo leads to synergistic NF-kappaB activation and invasive prostate carcinoma. Proc Natl Acad Sci USA 2009, 106(31):12962-12967

12. Kline CL, Shanmugavelandy SS, Kester M, Irby RB: Delivery of PAR-4 plasmid in vivo via nanoliposomes sensitizes colon tumor cells subcutaneously implanted into nude mice to 5-FU. Cancer Biol Ther 2009, 22:1831-1837

13. Burikhanov R, Zhao Y, Goswami A, Qu S, Schwarze SR, Rangnekar VM: The tumor suppressor Par-4 activates an extrinsic pathway for apoptosis. Cell 2009, 138(2):377-388

14. Moscat J, Diaz-Meco MT, Wooten MW: Of the atypical PKCs, Par-4 and p62: recent understandings of the biology and pathology of a PB1-dominated complex. Cell Death Differ 2009, 16(11):1426-1437

15. Moreno-Bueno G, Fernandez-Marcos PJ, Collado M, Tendero MJ, Rodriguez-Pinilla SM, Garcia-Cao I, Hardisson D, Diaz-Meco MT, Moscat J, Serrano M, Palacios J: Inactivation of the candidate tumor suppressor par-4 in endometrial cancer. Cancer Res 2007, 67:1927-1934

16. García-Cao I, Duran A, Collado M, Carrascosa MJ, Martín-Caballero J, Flores JM, Diaz-Meco MT, Moscat J, Serrano M: Tumour-suppression activity of the proapoptotic regulator Par4. EMBO Rep 2005, 6:577-583

17. Barradas M, Monjas A, Diaz-Meco MT, Serrano M, Moscat J: The downregulation of the pro-apoptotic protein Par-4 is critical for Ras-induced survival and tumor progression. EMBO J 1999, 18(22):6362-6369

18. Zhao Y, Burikhanov R, Qiu S, Lele SM, Jennings CD, Bondada S, Spear B, Rangnekar VM: Cancer resistance in transgenic mice expressing the SAC module of Par-4. Cancer Res 2007, 67:9276-9285

19. Srinivasan S, Ranga RS, Burikhanov R, Han SS, Chendil D: Par-4dependent apoptosis by the dietary compound withaferin A in prostate cancer cells. Cancer Res 2007, 67(1):246-253

20. Azmi AS, Ahmad A, Banerjee S, Rangnekar VM, Mohammad RM, Sarkar FH: Chemoprevention of pancreatic cancer: characterization of Par-4 and its modulation by 3,3' diindolylmethane (DIM). Pharm Res 2008, 25(9):2117-2124

21. Azmi AS, Wang Z, Burikhanov R, Rangnekar VM, Wang G, Chen J, Wang S, Sarkar FH, Mohammad RM: Critical role of prostate apoptosis response-4 in determining the sensitivity of pancreatic cancer cells to small-molecule inhibitor-induced apoptosis. Mol Cancer Ther 2008, 7(9):2884-2893

22. Mennone A, Alvaro D, Cho W, Boyer JL: Isolation of small polarized bile duct units. Proc Natl Acad Sci USA 1995, 92(14):6527-6531

23. Alvaro D, Barbaro B, Franchitto A, Onori P, Glaser SS, Alpini G, Francis H, Marucci L, Sterpetti P, Ginanni-Corradini S, Onetti Muda A, Dostal DE, De Santis A, Attili AF, Benedetti A, Gaudio E: Estrogens and insulin-like growth factor 1 modulate neoplastic cell growth in human cholangiocarcinoma. Am J Pathol 2006, 169(3):877-888

24. Mancino A, Mancino MG, Glaser SS, Alpini G, Bolognese A, Izzo L, Francis H, Onori P, Franchitto A, Ginanni-Corradini S, Gaudio E, Alvaro D: Estrogens stimulate the proliferation of human cholangiocarcinoma by inducing the expression and secretion of vascular endothelial growth factor. Dig Liver Dis 2009, 41(2):156-163

25. Schroeder A, Mueller O, Stocker S, Salowsky R, Leiber M, Gassmann M, Lightfoot S, Menzel W, Granzow M, Ragg T: The RIN: an RNA integrity number for assigning integrity values to RNA measurements. BMC Mol Biol 2006, 7:3

26. Cantafora A, Blotta I, Rivabene R, Pisciotta L, Bertolini S: Evaluation of RNA messengers involved in lipid trafficking of human intestinal cells by reverse-transcription polymerase chain reaction with competimer technology and microchip electrophoresis. S Electrophoresis 2003, 24:3748-3754

27. Vandesompele J, De Preter K, Pattyn F, Poppe B, Van Roy N, De Paepe A, Speleman F: Accurate normalization of real-time quantitative RT-PCR data by geometric averaging of multiple internal control genes. Genome Biol 2002, 3(7):RESEARCH0034

28. Onori P, Alvaro D, Floreani AR, Mancino MG, Franchitto A, Guido M, Carpino G, De Santis A, Angelico M, Attili AF, Gaudio E: Activation of the IGF1 system characterizes cholangiocyte survival during progression of primary biliary cirrhosis. J Histochem Cytochem 2007, 55(4):327-334

29. Lee TJ, Jang JH, Noh HJ, Park EJ, Choi KS, Kwon TK: Overexpression of Par-4 sensitizes TRAIL-induced apoptosis via inactivation of NF-kappaB and Akt signaling pathways in renal cancer cells. J Cell Biochem 2010, 109(5):885-895

30. Lin HI, Lee YJ, Chen BF, Tsai MC, Lu JL, Chou CJ, Jow GM: Involvement of Bcl-2 family, cytochrome $\mathrm{c}$ and caspase 3 in induction of apoptosis by beauvericin in human non-small cell lung cancer cells. Cancer Lett 2005, 230(2):248-259

31. Mellier G, Huang S, Shenoy K, Pervaiz S: TRAILing death in cancer Mol Aspects Med 2010, 31(1):93-112

32. Chen Y, Xu J, Jhala N, Pawar P, Zhu ZB, Ma L, Byon CH, McDonald JM: Fas-mediated apoptosis in cholangiocarcinoma cells is enhanced by 3,3'-diindolylmethane through inhibition of AKT signaling and FLICE-like inhibitory protein. Am J Pathol 2006, 169(5):1833-1842

33. Zhao Y, Rangnekar VM: Apoptosis and tumor resistance conferred by Par-4. Cancer Biol Ther 2008, 7(12):1867-1874

34. Page G, Kogel D, Rangnekar V, Scheidtmann KH: Interaction partners of DIk/ZIP kinase: co-expression of DIk/ZIP kinase and Par-4 results in cytoplasmic retention and apoptosis. Oncogene 1999, 18:7265-7273

35. Díaz-Meco MT, Municio MM, Frutos S, Sanchez P, Lozano J, Sanz L, Moscat J: The product of par-4, a gene induced during apoptosis, interacts selectively with the atypical isoforms of protein kinase $\mathrm{C}$. Cell 1996, 86:777-786

36. Diaz-Meco MT, Lallena MJ, Monjas A, Frutos S, Moscat J: Inactivation of the inhibitory kappaB protein kinase/nuclear factor kappaB pathway by Par-4 expression potentiates tumor necrosis factor alphainduced apoptosis. J Biol Chem 1999, 274(1):9606-9612

37. Chung JY, Hong SM, Choi BY, Cho H, Yu E, Hewitt SM: The expression of phospho-AKT, phospho-mTOR, and PTEN in extrahepatic cholangiocarcinoma. Clin Cancer Res 2009, 15(2):660-667

38. Xu X, Kobayashi S, Qiao W, LiC J: Induction of intrahepatic cholangiocellular carcinoma by liver-specific disruption of Smad4 and Pten in mice. Clin Invest 2006, 116(7):1843-1852

39. Kaul MK, Kumar A, Ahuja A, Mir BA, Suri KA, Qazi GN: Production dynamics of Withaferin A in Withania somnifera (L.) Dunal complex. Nat Prod Res 2009, 23(14):1304-1311

40. Yu Y, Hamza A, Zhang T, Gu M, Zou P, Newman B, Li Y, Gunatilaka AA, Zhan CG, Sun D: Withaferin A targets heat shock protein 90 in pancreatic cancer cells. Biochem Pharmacol 2010, 79(4):542-551

41. Shaib YH, El-Serag HB, Davila JA, Morgan R, McGlynn KA: Risk factors of intrahepatic cholangiocarcinoma in the United States: a case-control study. Gastroenterology 2005, 128(3):620-626 